nicely direct and regulate the pressure. This contrivance caused no dyspnoea and completely checked all bleeding.

\section{HOSPITAL FOR EPILEPSY AND PARALYSIS, REGENT'S-PARK.}

SEQUEL TO THE CASE OF EXCISION OF A TUMOUR FROM THE BRAIN.

(Under the care of Dr. HUGHES BENNETT and Mr. RICKMAN J. GODLEE.)

IN our issue of Dec. 20 th we supplied our readers with some notes of a case in which a tumour had been excised from the substance of the brain on Nov. 25th, with the condition of the patient up to the 15 th ult.; to which date the progress of the case had been entirely satisfactory. We are now enabled to give the sequel, which has unfortunately terminated in the death of the patient. On the morning of Dec. 16th the man was suddenly seized with a rigor, followed by fever, sickness, and pain in the head. A hernia cerebri of large dimensions supervened. The pyrexia increased and continued, the patient emaciated, gradually sank, and died on Dec. 23rd, the intelligence remaining intact to the last.

On post-mortem examination meningitis was found at the lower border of the wound, spreading downwards towards the base of the brain on the same side, the whole of which was inflamed and covered with plastic lymph. With the exception of the loss of cerebral tissue, caused by the operation, the brain was otherwise practically normal. We understand that the details of this interesting case will be brought before the profession in due course.

\section{DUNDEE ROYAL INFIRMARY.}

ACUTE CEREBRAL MENINGITIS; RECOVERY.

(Under the care of Dr. SINCLAIR.)

Fon the following notes we are indebted to Dr. A. M. Stalker, pathologist, late house-surgeon :--

J. R-_-, aged eleven, mill-worker, was admitted on March 31st, $188^{\circ}$, suffering from an illness which had commenced five days before. There was no history of illness or injury previous to this. The symptoms were pain and stiffness in the neck, especially on the right side, with general malaise and weakness. 'The boy's friends said he had been carrying unusually heavy loads on his shoulders two or three days before he began to complain.

State on admission.--Patient has a feverish look; lips dry and cracked; tongue dry, furred on dorsum, and glazed at tip and edges; appetite gone; bowels constipated, motions natural in colour; some abdominal pain; heart and lungs normal. Pulse 108; respiration 28; evening temperature 103.4\%. Pupils contracted and equal. Tache cérébrale brought out on abdomen and arms. Patient has tendency to delirium ; never lifts his head, complains of frontal headache, cries out suddenly, the cry having a cerebral character. There are diffuse stiffness and pain in the neck, most marked on the right side. For some days the patient continued in much the same state, being generally delirious at night and quieter during the day. Bromide of potassium and opiates were given when necessary, cold lotions were applied continuously to the head, and a blister raised on the nape of the neck. Temperature in the morning $101^{\circ}$ to $102^{\circ}$, in the evening $103^{\circ}$ to $1038^{\circ}$; respiration normal pulse 112 to 120 , regular. From April 9th to 17 th there was some improvement, the pulse and temperature being nearer the normal, and the patient being quieter. The pupils were now unequal in size, the right being larger than the left. At this time the temperature rose on two successive nights to above $104^{\circ}$. Croton oil was effectually applied to the back of the head. The symptoms showed general improvement, though slow, till the end of April, when the temperature fell to normal, and the other symptoms disappeared. Bowels remained normal all through. Dismissed on June 10th, quite well.

Remarks by Dr. SinclarR.-That the possibility of enteric fever was never seriously entertained will excite no surprise after a perusal of the clinical history of this case. Was it tubercular meningitis? Was it an instance of that malady which I am not alone in believing to be extremely rareviz., acute simple idiopathic meningitis? Or was it a case of meningitis due to an obvious external cause? I must say that tubercular meningitis has never come forcibly before my mental vision in a case of this description, least of all, perhaps, in the earlier stages of its course. That the patient did not die does not by any means exclude the possibility of a tubercular origin; but the age was rather against such an explanation, because, although the disease sometimes occurs beyond the age of ten, it is much commoner before that age, and commoner still between the ages of two and five. It will be observed also that there was no prodromal stage, with its wasting of the adipose and muscular tissues, its languor, mental torpor, unstable emotions, and irritable temper. The pulse was never slow and irregular in the stage immediately succeeding the stage of invasion. The temperature at the time the patient came under observation and subsequently was nearly always too high for this explanation. The idiopathic theory seems to me untenable so long as any other agency can account for the morbid condition. We had here to deal with a previously healthy boy eleven years old. A sudden invasion, a well-marked attack of cerebral meningitis, probably an effusion of lymph, and a complete mental and physical recovery. We had a history of an unusually heavy load having been carried on the shoulders a few days before the onset of the attack; and this I am convinced gives us the solution of the difficulty. The unusual exertion caused, I believe, a determination of blood to the head, and initiated a sequence of events very similar to those which follow closely upon that vaso-motor paralysis which is apt to be induced by exposure to the direct rays of the sun or artificial heat. The recovery was complete, although slow. Jiow much of the result was due to good nursing and careful feeding and how much to the local treatment I am not prepared to say.

CEREBRAL ABSCESS DUE TO CHRONIC SUPPURATION OF THIE MIDDLE EAR; DEATH; AUTOPSY.

(Under the care of Dr. Sincharr.)

For the following notes we are indebted to Dr. D. J. Reid, late house-surgeon:-

J. Y--, aged twenty-two, carter, admitted on August 17th, 1883, with the following history:--The patient had a rigor three days ago and another last night. Since then he has complained of pain in his head, especially on the left side.

On admission he was so sick that he had to lie down at once. Tongue covered with a creamy fur, and the papillæ enlarged. There was no eruption on the body. His aspect was heavy; pupils natural. He had slight photophobia. Temperature $102^{\circ}$; pulse 144; uxine acid, sp. gr. 1024, with slight albumen.

August 18th.-Temperature $103.6^{\circ}$; pulse 84 . Ordered dry cupping to the nape of the neck; hair cut short; icebag to head. Ordered twenty grains of bromide of potassium every six hours. Had a rigor at 1.45 P.x., and was livid. Morning temperature $103.4^{\circ}$; evening, $101^{\circ} 6^{\circ}$, and at midnight $103 \cdot 4^{\circ}$.

19th.-Temperature $101 \cdot 2^{\circ}$; pulse 108; slept fairly well; headache gone. Evening temperature $99 \cdot 8^{\circ}$; had a rigor at 7.35 P.M., when the temperature rose to $103^{\circ}$.

20th.-2 A.M., temperature $105^{\circ} 6^{\circ} ; 9$ A.M., $103^{\circ}$; has had diarrhoea since last night; stools of a "pea-soup " character; 6 P.M., temperature $98^{\circ} 4^{\circ}$.

21 st. -9 A.M., temperature $984^{\circ}$; 6 P.M., temperature $101^{\circ}$; bowels opened twice to-day.

22 nd. 9 A.M., temperature $99.2^{\circ} ; 6$ P.M., $100 \cdot 4^{\circ}$; bowels opened twice; severe headache.

23rd.-Morning temperature $102^{\circ}$; spleen enlarged ; slight cough; lungs normal. Ordered a diaphoretic mixture twice daily. Evening temperature $1044^{\circ}$; bowels opened once to-day.

24 th.-Morning temperature $100^{\circ}$; evening, $100^{\circ}$; rigor this forenoon.

25th.-Died this morning at 6.15 .

Autopsy.-Abdomen: No peritonitis; omentum injected; intestines filled with loose dark yellow stools; considerable injection of upper half of large and lower two feet of small intestine; some enlargement of solitary glands; no ulceration; spleen large and congested; liver and kidneys normal. Thorax: Heart and lungs nommal. Head: Dura mater slightly adherent posteriorly. On removing the brain small collection of ill-smelling pus was found over the upper surface of the petrous portion of the left temporal bone, between the bone and the dura mater. There was some inflammation and very superficial softening of the temporo-sphenoidal convolutions in the immediate vicinity of the abscess. On sawing through the petrous portion of 